\title{
Assessment of Students Support Services Centre Approach to Screening, Brief Intervention and Referral to Treatment of Substance Abuse Management in a Private Institution of Higher Learning
}

\author{
Okondu Ogechukwu Emmanuel ${ }^{1,2}$, Afolabi Rachael Ayomide ${ }^{1}$, Lazarus Phebe Victoria ${ }^{1}$, Okondu Emmanuel \\ Confidence $^{3}$, Khadija Abubakar ${ }^{4}$, Banjo Oluwafikayomi Opeyemi ${ }^{5}$, Ikonta Peter $\mathrm{C}^{6}$, Chigeru Chinyere Florence ${ }^{6}$, \\ Iloma Unwobuesor Richard ${ }^{7} \&$ Okafor Ukamaka Gladys ${ }^{8}$ \\ ${ }^{1}$ Department of Public Health, Babcock University, Ilishan-remo, Ogun State, Nigeria \\ ${ }^{2}$ Faculty of Education, Department of Human Kinetics and Health Education, Nnamdi Azikiwe University, Awka, \\ Anambra State, Nigeria \\ ${ }^{3}$ Jotna Nigeria Limited, 12 Akinwande Street, Off Badagry Express way, Lagos, Nigeria \\ ${ }^{4}$ University of Sheffield, South Yorkshire, England, United Kingdom \\ ${ }^{5}$ Department of Social Work and Human Services, Babcock University, Ilishan-remo \\ ${ }^{6}$ Student Support Center, Babcock University, Ilishan-remo, Ogun State, Nigeria \\ ${ }^{7}$ Rivers State College of Sciences and Management Technology, Port-Harcourt, Nigeria \\ ${ }^{8}$ Pharmacists Council of Nigeria, Lagos, Nigeria \\ Correspondence: Okondu Ogechukwu Emmanuel, Department of Public Health, Babcock University, \\ Ilishan-remo, Ogun State, Nigeria.
}

Received: July 25, 2020 Accepted: September 10, 2020 Online Published: October 9, 2020

doi:10.5539/gjhs.v12n12p9

URL: https://doi.org/10.5539/gjhs.v12n12p9

\begin{abstract}
Substance abuse among young adults is a major public health issue which can cause significant damage to their mental health. The screening, brief, interventions and referral to treatment (SBIRT) is a public health prevention tool used in identifying persons at risk of substance use and abuse. This study assessed the approach to screening, brief intervention and referral to treatment of substance abuse management in a higher institution of learning. The study adopted a qualitative key informant's interviewer assessment method. Key informants from the Student Support Service (SSS) Centre were interviewed to assess the SBIRT management approach of substance abuse in a university setting. The interview guide had a total of 5 themes with 8 questions and 14 follow-up questions. Interviews and observation of key informants was used to obtain research information. Data was analyzed using thematic analysis. This study revealed that the study population utilized reliable drug tests, students' performance, behavior and appearance of the students as an approach to screening students for substance abuse. Management was dependent on level of risk of the student determined from the screening process. Substance use disorders varying from moderate to high risk were given counselling therapy; patients with severe risk dependency were referred to specialty treatment (rehabilitation) for further treatment. The SBIRT approach in the treatment of students at risk of substance abuse have been found to be useful. There are however challenges with students complying to treatment which needs to be addressed.
\end{abstract}

Keywords: substance abuse, faith-based institution, screening, intervention, management

\section{Introduction}

Substance abuse according to the World Health Organization refers to the harmful or hazardous use of psychoactive substances, including alcohol and illicit drugs (WHO, 2020).According to the United Nations Office on Drugs and Crime (UNODC) World Drug Report 2018, substance use and abuse is an issue of public health importance as it accounts for $76 \%$ of deaths where there was a drug use disorder. Globally, an estimated 275 million people or 5.6\% of the population aged 15-64 years were using drugs in 2016 (UNODC, 2018).

Among young adults aged 10-24, substance abuse is on the rise and has the potential to affect their cognitive and emotional development (Degenhardt et al., 2016).Research shows that drug use and abuse is higher among 
adolescents and younger adults than other age group with the peak level seen among young people between ages 18-25. Globally an estimated 2.6 million young people die each year due to preventable causes such as substance abuse. In Nigeria, the situation is not any different with prevalence rate among young people ranging from $15.3 \%$ to $69.3 \%$ (Idowu et al., 2018).

Several factors have been associated with substance abuse. They include personal factors such as relaxation and experimental purpose, academic pressure, peer pressure and even socioeconomic and physical environment among others (UNODC, 2018; Idowu et al., 2018). The consequences are however devastating and can be short term such as change in appetite, mood, blood pressure, heart rate, psychosis, overdose and even death or long term consequences such as heart or lung diseases, cancer, mental illness, HIV/AIDS, hepatitis, and even addiction(NIDA, 2017).

Some studies have considered some strategies in the prevention of substance abuse among young adults; One of such strategy is the Screening, Brief Intervention, and Referral to Treatment (SBIRT), a public health framework approach used to identify and deliver services to those at risk for substance-use disorders, depression, and other mental health conditions. SBIRT involves screening to assess the patient for substance use, brief intervention using motivational interviews to educate the patient on the consequences of substance abuse and help the patient move towards behavior change, identification of the suitable level of treatment, and referral to treatment if the patient needs specialty care (SAMHSA, 2011; Hargraves et al., 2011).

The use of SBIRT approach to substance abuse management has reduced the cost of health problems associated with substance abuse in different countries across the world, most especially in developed countries who have more than enough facilities to practice the public health approach.The need for the elimination of substance abuse is required for the quality of the future of students involved in the illicit use of drugs.

This study therefore assessed the student support services centre approach to Screening, Brief Intervention and Referral to Treatment of substance abuse management at Babcock University.

\section{Methods}

\subsection{Data Sources and Study Population}

This study obtained data from the Student Support Service (SSS) Centre in Babcock University, a Seventh Day Adventist higher institution located in Ilishan-Remo, Ogun State, Nigeria. The study employed the qualitative method of data collection to assess Students Support Services Centre (SSS) approach to screening, brief intervention and referral to treatment of substance abuse management. Key informants from the Student Support Service (SSS) Centre were interviewed in this study to obtain data on screening approach, brief intervention approach and referral to treatment approach for substance use.

\subsection{Sample Size and Sampling Technique}

This study was a qualitative study hence did not require a sample size calculation. A total of 8 participants were selected as key informants from the Student Support Service (SSS) Centre to participate in this study based on the criteria that was set. Only staff who were responsible for the management of students with substance abuse disorders were included for the purpose of this study while administrative staff were excluded.

\subsection{Instrumentation and Data Collection}

An in-depth interview guide was prepared and used to obtain data from study participants. The themes and sub-themes which were identified in this study were guided by the Screening Brief Intervention and Referral to treatment (SBIRT) model. The interview guide had a total of 5 themes with 7 questions and 13 follow-up questions. A total of three (3) trained research assistants aided this study using other instruments such as tape recorders and writing materials to record and write down observations. Two sections were held to further provide clarity. Prior to the study, ethical approval was obtained from the Babcock University Health and Research Ethical Committee (BUHREC). To ensure safety and anonymity of the participants, names were not included and informed consent was obtained from all participants. Participation in this research was entirely voluntary.

\subsection{Data Analysis}

Data was analyzed using thematic analysis which is performed through the process of coding in six phases to create meaningful patterns. The phases were familiarized with the data, initial codes were generated, and themes were reviewed, defined and named in order to produce the final report of the analysis. 


\section{Results}

Table 1. An in-depth interview guide on the assessment of students support services center approach to screening, brief intervention and referral to treatment of substance abuse management.

\begin{tabular}{|c|c|}
\hline \multicolumn{2}{|c|}{ Theme 1. Exploring respondents view on screening on substance abuse (low risk, medium risk and high risk) } \\
\hline $\begin{array}{l}\text { How do you identify a person's level of risk } \\
\text { to substance use abuse? }\end{array}$ & $\begin{array}{l}\text { Follow up questions } \\
\text { What type of treatment should be given irrespective of the patient's level } \\
\text { of risk? } \\
\text { What alternative treatment is advised when the patient/client is not } \\
\text { responding to the usual treatment? }\end{array}$ \\
\hline \multicolumn{2}{|c|}{ Theme 2. Exploring respondents view on brief interventions on substance abuse } \\
\hline $\begin{array}{l}\text { Why is there a need for brief interventions } \\
\text { for patients? }\end{array}$ & $\begin{array}{l}\text { What are your intentions in carrying out interventions based on a patient's } \\
\text { level of risk to substance use abuse? } \\
\text { Could you say the intention towards intervention is based on institutional } \\
\text { mission and why? Or based on the client's request or based on the } \\
\text { situation you find the patient? } \\
\text { What strategies would you use depending on the level of risk involved? } \\
\text { How will you handle a patient who refuses to comply well with the } \\
\text { interventions? }\end{array}$ \\
\hline \multicolumn{2}{|c|}{ Theme 3. Exploring respondents view on brief treatment on substance abuse } \\
\hline $\begin{array}{l}\text { Which category (level of risk) of } \\
\text { clients/patients is brief treatment given to? } \\
\text { What do brief treatment of substance use } \\
\text { entail? }\end{array}$ & $\begin{array}{l}\text { How do you give patients brief treatment? } \\
\text { Why do patients need to be treated? } \\
\text { Is there any other alternative method available to treat this category of } \\
\text { patients? }\end{array}$ \\
\hline \multicolumn{2}{|c|}{ Theme 4. Exploring respondents view on referral to treatment on substance abuse } \\
\hline $\begin{array}{l}\text { What category of patients are referred to } \\
\text { treatments? } \\
\text { From what stage can a patient/client be } \\
\text { referred for further treatment on substance } \\
\text { use abuse? } \\
\text { What type of facility is required for such } \\
\text { cases? }\end{array}$ & $\begin{array}{l}\text { Follow-up questions } \\
\text { Why are these category of patients referred to treatment? } \\
\text { Would their referral to treatment restrict them from certain behaviours? } \\
\text { How can this category of patients be supported in order to help them } \\
\text { abstain completely from substance abuse use? } \\
\text { Outside of the supposed substance use Clinic, which other support systems } \\
\text { are available? } \\
\text { Who bears the cost of treatment per client/patient }\end{array}$ \\
\hline \multicolumn{2}{|l|}{ Theme 5. Recommendations } \\
\hline & ions to give? \\
\hline
\end{tabular}

Theme 1. Exploring respondents view on screening on substance abuse (low risk, medium risk and high risk)

This comprises of an evidence-based questionnaire which is used by healthcare providers to identify a patient's placement on a scale of substance abuse use, ranging from risky, to problematic, to the disease of addiction. The screening yields a numerical score showing the severity of abuse and guides the level of intervention. In some cases, screening alone can raise awareness, reduce use, and have preventive effects.

"The student's level of risk can be identified through the appearance, if the person is sweating, from the behaviour, the person may be required to take a drug test and also through the student's performance."[Section1]

"The type of treatment that can be given to a student with substance use disorder irrespective of the student's level of risk is counselling and also the student may be advised to invite his or her parents. Students are also advised to go for rehabilitation for correction and also to prevent the student from influencing other students on campus."[Section1]

"In order to identify a patient's risk of substance abuse, a drug test will be carried out. "[Section 2]

\section{Theme 2. Exploring respondents view on brief interventions on substance abuse}

People displaying mild symptoms receive a 15-30-minutes intervention. They are given their screening score, discuss their risks and motivations, and establish goals and strategies to reduce use. The brief intervention is 
shown to significantly reduce substance use.

"There is a need for brief interventions for patients who have substance use disorder in order for them to change their behaviour. It is also for their own benefit, which is to see them do well academically and also for them to have a brighter future." [Section 1]

"The intention towards the intervention for the student is based on the situation of the patient." The strategies that is used based on the individual's level of risk is by identifying the level of risk, giving counselling therapy, if it does not work out for the patient or if the patient does not comply to the intervention, the parents will be invited to make them aware of the situation of the student and later advice the student to go for rehabilitation." [Section 1]

"Brief interventions is needed to prevent the patient from being addicted. For example, a patient who has a low risk of substance abuse, after brief interventions, it is expected that the patient should be able to pause the behaviour and not continue further." [Section 2]

"To encourage and support the patient to choose abstinence to prevent further complications. Intervention is given to patients based on the result from their drug tests. [Section 2]

Theme 3. Exploring respondents view on brief treatment on substance abuse

People who are diagnosed with the disease of addiction, or with complicated psychiatric symptoms, are referred to specialty treatment right away.

"Brief treatment is given to patients at low risk. The students are advised to go for rehabilitation for treatment, after the treatment, the patient can come back to school to continue his or her studies. "[Section 1]

"Patients need to be treated to ensure that they continue with their education and also to make them perform well in their academics." [Section 1]

"There are no other significant alternatives; the important thing for the students to do is for them to go to the rehabilitation centre." [Section 1]

"Depending on the level of risk involved the patient would be screened first to know the level of risk, if the patient is at a high risk, the patient would be given brief interventions and be referred to treatment (rehabilitation centre) immediately." [Section 2]

"Brief Treatment should be given to the patient irrespective of his/her level of risk. If the patient is not responding to treatment, the patient would be advised to go for rehabilitation." [Section 2]

"Brief treatment is given to patients with low or moderate risks to prevent addiction and to enable them abstain from substance abuse. "[Section 2]

"Patients are given brief treatment through counselling therapy making them know the complications of their behaviours." [Section 2]

"The patients need treatment to enable them abstain completely from substance abuse and also to prevent them from further implications that may result from the behaviour such as poor academic failure, truancy and dropping out of school completely." [Section 2]

"Another method that is available to treat low and moderate risk patients is to refer them to rehabilitation especially when they are not responding well to brief treatments. "[Section 2]

Theme 4. Exploring respondents view on referral to treatment on substance abuse

People who are diagnosed with the disease of addiction, or with complicated psychiatric symptoms, are referred to specialty treatment right away.

"Patients at medium and high risk of substance use are referred to treatments because they need to reduce their level of risk and gradually abstain from substance abuse. "[Section 1]

"Yes, their referral to treatment would restrict them from certain behaviours to enable them abstain from substance abuse." [Section 1]

"The category of patients that are referred to treatments can be supported by counselling them first in order to enable them respond well to the treatment." [Section 1]

"The support system available is the Students Support Service Centre and the rehabilitation centre." [Section 1]

'The students are responsible for the cost of the treatment given to them and the cost for this treatment is affordable." [Section 1] 
"In most cases, patients at high risk are the ones referred to treatments most especially when they are not complying with the primary treatments given to them at the Students Support Services Centre." [Section 2]

"A patient can be referred to treatment at the early stage of detection depending on how well the patient will respond to brief treatment." [Section 2]

"Patients who are referred to treatment would be restricted from certain behaviours in order to help them abstain completely from the behaviour." [Section 2]

"Asides from the clinics, the rehabilitation centre is also available and the students bear the cost of payment which is very affordable." [Section 2]

\section{Theme 5. Recommendations}

"Students should abstain from the behaviour of substance abuse as soon as they notice that they are into the act." [Section 1]

"The students who engage themselves in the buying and selling of hard drugs such as codeine should try to find out if the supplier loves them or loves their money. The fact is most of these suppliers don't use these hard drugs, they only supply them to make money at the expense of the health of the students." [Section 2]

"Students should be aware of the truth that substance will do them no good (awareness)." [Section 2]

"Parents should endeavour to monitor their children strictly to avoid certain behaviours and also preventing them from becoming habits in the lives of their children." [Section 2]

Table 2. Summary of key informants responses on student's support services centre approach to sbirt

\begin{tabular}{|c|c|c|}
\hline Themes & Variables & Participant's responses \\
\hline 1 & $\begin{array}{l}\text { Screening (low risk, moderate risk, moderate to high } \\
\text { risk and Severe risk dependency) }\end{array}$ & $\begin{array}{l}\text { By conducting a drug test. } \\
\text { By checking out the appearance and behaviour. } \\
\text { Students' performance. }\end{array}$ \\
\hline 2 & Brief Intervention (Moderate risk) & $\begin{array}{l}\text { Required to prevent addiction. } \\
\text { To prevent further implications. } \\
\text { To encourage abstinence. }\end{array}$ \\
\hline 3 & Brief Treatment (Moderate to high risk) & $\begin{array}{l}\text { It is given to patients with low or moderate risk of } \\
\text { substance abuse. } \\
\text { To ensure them continue their education. } \\
\text { For them to improve their academic performance. }\end{array}$ \\
\hline 4 & Referral to Treatment (Severe risk dependency) & $\begin{array}{l}\text { It is given to patients with moderate and high risk of } \\
\text { substance abuse. } \\
\text { This would restrict them to certain behaviours. }\end{array}$ \\
\hline 5 & Recommendations & $\begin{array}{l}\text { As soon as the student notice that he or she has a } \\
\text { substance abuse disorder, abstinence should occur. } \\
\text { Substance abuse will bring no good to the students in this } \\
\text { act. }\end{array}$ \\
\hline
\end{tabular}

\section{Discussions}

The Students Support Services Centre Screening approach were carried out through reliable drug tests, the students' performance, behaviour and appearance. The result (level of risk) from the screening process determines whether the student needs brief intervention, or needs to be given brief treatment or referred to specialty treatment. This process aims to reduce the level of risk of the patient and also help the patient abstain from the behaviour completely. Patients with severe risk dependency are referred to rehabilitation centres for specialty treatment in order to enable them abstain from substance abuse and develop healthy behaviours.

Students who engage themselves in substance abuse are liable to die at a young age, and also perform poorly academically because of the effect of the substance on their cognitive state. Studies reveal that individuals with substance abuse disorders are at risk of psychiatric disorders, suicide attempts and even death at a younger age compared to people without substance use disorder (Esang \& Ahmed, 2018).Substance abuse could lead to high crime rates in the society such as robbery, rape and other juvenile acts. As earlier discussed, if substance abuse is not curbed in the institution of learning, students with substance use problems may influence other student. 
This study showed how the screening, brief intervention and referral to treatment approach was carried out in the Students Support Services Centre (SSS). The patients with substance use disorders varying from moderate to high risk were given counselling therapy; patients with severe risk dependency were referred to specialty treatment to enable them abstain from substance abuse in order to prevent further complications and develop healthy behaviours. This study is limited to only students in Babcock University which is the main focus and it didn't address the root cause of substance use and abuse, it covered majorly how the behaviour is managed in the Students Support Services Centre (SSS).

During the screening process, students get tested to know if they have any content of hard drugs in their system, some may show signs through their appearance and behaviour, while others may be due to poor academic performance. The patients that are at a very low risk of substance use and abuse may not require any further interventions. It is however advised that students with moderate to high risk of substance abuse undergo brief intervention such as counselling therapy to help them abstain from the act depending on their level of risk. Some students may persist in the behaviour (moderate to high risk) which will require brief treatment in other to observe compliance and abstinence. In situations where students do not comply, the Students Support Services Centre refer them with a rehabilitation centre for further treatments. SBIRT has been found to be effective in various medical settings, including the emergency department (Agerwala \& McCance, 2018; Horn, Crandall, Forcehimes, French, \& Bogenschutz, 2012).

Brief intervention (Counselling therapy) is given to patients that are at low risk or moderate risk of substance use disorder. This is done in other to prevent the patients from getting addicted ultimately improving their academic performances. Also, it reduces the risk to substance abuse and set up goals and strategies that the patient can adopt to stop the behaviour. BI has been shown to reduce subsequent alcohol use, marijuana use and problems associated with substance abuse (Woolard, 2013). If the patient refuses to comply, the parents would be invited to make them aware of the behaviour and possible solutions. Tobacco, alcohol and illicit drugs are among the top 20 factors for ill-health identified by the World Health Organization (WHO, 2002).

This study reveals that patients at any level of risk could be given brief treatment to enable them abstain from the behaviour (substance abuse) and improve academic performances. The 2013 National survey on drug use and health revealed that less than $10 \%$ of adolescents in need of specialty substance use treatment receive it (CBHSQ, 2013). It would also help to reduce the crime rate of youths especially adolescents in the society they find themselves.

Students who are referred to treatment most times are addicted to substance abuse which implies that they have a very high level of dependency on substance abuse and they need to be rehabilitated to get proper treatment that will help them abstain gradually from the behaviour. The psychiatrists have their specialized way of taking care of patients at this level of risk based on their knowledge and experience.

The study participants expressed that most students are not aware of the fact that the suppliers of these drugs are not concerned about their health and future, they are only after their money. Most of these suppliers don't even make use of these drugs but they sell them to make a living for themselves without considering the implications. Study reveals that young people who are highly informed on the risk and harm associated with drug use would eventually have high perception of adverse consequences and initiate drug use prevention (Ikonta, Atulomah, \& Okondu, 2020). More awareness of the complications of substance abuse should be given to prevent students from the behaviour.

Parents in general also have a leading role to play in the upbringing of their children enabling them to have an identity and feel loved in order to improve their self-esteem. They need to monitor the kind of friends their children keep in their schools as it contributes to the likelihood of them engaging in the behaviour.

\section{Conclusions}

This study shed light on the views of substance abuse management and has identified the challenges that were faced by the Substance Abuse Unit of the Students Support Services Centre in the management of substance abuse. This would certainly be noted and addressed for a better approach to managing the cause of the challenges. The Students Support Services Centre have relatively positive views based on how they manage clients with substance use disorder and how these clients respond to treatments. Only a few statements were negative as regards the root cause of the problem of substance abuse and why it's now a trend. Possibly this could be changed overtime through several interventions from the school and also health organizations. The Students Support Services Centre (SSS) also made reference to the stable punishment for drug users on campus which is suspension for a year or two years which also has its consequences. 


\subsection{Recommendations}

Based on the findings of this study, the following recommendations are made to the student support service, social workers, healthcare professionals, the various ministries of health and any other organization or individual in a position to make the necessary changes;

1). There should be more awareness on substance abuse and the dangers involved since it's something that is common in our society today.

2). Students who have been identified to be at high risk of substance abuse should be properly monitored and counselled

3). Parents through the Parent-Teacher Association (PTA) Forum could be encouraged to show care and make their children feel loved and also monitor the kind of friends their wards move with since majority of people involved in substance abuse is as a result of peer pressure and lack of love from their family.

4). The students should be aware that in most cases, the suppliers of the drugs are not users, they also don't care about their health, and they are only after the money.

5). Rehabilitation programs for substance abuse should be coordinated and an inventory of rehabilitation and treatment programs be maintained to ensure optimum follow up of client or patient.

6). Services for substance abuse should be integrated into comprehensive healthcare system in communities to ensure that persons with diseases have access to treatment and rehabilitation.

\section{Competing Interests Statement}

The authors declare that there are no competing or potential conflicts of interest.

\section{References}

World Health Organization. Substance abuse. 2020. Retrieved from https://www.who.int/topics/substance_abuse/en/

United Nations Office on Drugs and Crime. World Drug Report. 2018. Retrieved from https://reliefweb.int/report/world/unodc-world-drug-report-2018

Degenhardt, L., Stockings, E., Patton, G., Hall, W. D., \& Lynskey, M. (2016). The increasing global health priority of substance use in young people. The Lancet, 3(3), 251-264. https://doi.org/10.1016/S2215-0366(15)00508-8

Idowu, A., Aremu, A. O., Olumide, A., \& Ogulaja, A. O. (2018). Substance abuse among students in selected secondary schools of an urban community of Oyo-state, South West Nigeria: implication for policy action. African Health Sciences, 18(3), 776-785. https://doi.org/10.4314/ahs.v18i3.36

National Institute on Drug abuse (2017). Health Consequences of Drug Misuse. Retrieved from https://www.drugabuse.gov/related-topics/health-consequences-drug-misuse

Substance Abuse and Mental Health Services Administration. (2011). Screening, Brief Intervention, and Referral to Treatment (SBIRT). Retrieved from http://www.samhsa.gov/prevention/SBIRT/index.aspx

Hargraves, D., White, C., Frederick, R., Cinibulk, M., Peters, M., Young, A., \& Elder, N. (2017). Implementing SBIRT (Screening, Brief Intervention and Referral to Treatment) in primary care: lessons learned from a multi-practice evaluation portfolio. Public Health Rev, 38, 31. https://doi.org/10.1186/s40985-017-0077-0

Esang, M., \& Ahmed, S. (2018). A Closer Look at Substance Use and Suicide. The American Journal of Psychiatry, 13(6). 6-8. https://doi.org/10.1176/appi.ajp-rj.2018.130603

Agerwala, S. M., \& McCance-Katz, E. F. (2012). Integrating Screening, Brief Intervention, and Referral to Treatment (SBIRT) into Clinical Practice Settings: A Brief Review. J Psychoactive Drugs, 44(4), 307-317. https://doi.org/10.1080/02791072.2012.720169

Horn, B. P., Crandall, C., Forcehimes, A., French, M. T., \& Bogenschutz, M. (2017). Benefit-Cost Analysis of SBIRT Interventions for Substance Using Patients in Emergency Departments. J Subst Abuse Treat, 79, 6-11. https://doi.org/10.1016/j.jsat.2017.05.003

Woolard, R., Baird, J., Longabaugh, R., Nirenberg, T., Lee, C. S., Mello, M. J., \& Becker, B. (2013). Project reduce: reducing alcohol and marijuana misuse: effects of a brief intervention in the emergency department. Addictive behaviors, 38(3), 1732-1739. https://doi.org/10.1016/j.addbeh.2012.09.006

World Health Organization (2002). The World Health Report 2002. Reducing Risks, promoting healthy life. W H 
O. Geneva.

Center for Behavioral Health Statistics and Quality (CBHSQ), Substance Abuse and Mental Health Services Administration (SAMHSA), U.S. Department of Health and Human Services (HHS), and by RTI International. Results from the 2013 National Survey on Drug Use and Health: Summary of National Findings. Retrieved from https://www.samhsa.gov/data/sites/default/files/NSDUHresultsPDF WHTML2013/Web/NSDUHresults2013.pdf

Ikonta, P. C., Atulomah, B. C., Okondu, O. E., \& Atulomah, N. O. (2020). Information-Adequacy, Motivation and Behavioral-Skills as Determinants of Substance-Use Prevention among Undergraduates in Babcock University, Ilishan-Remo, Nigeria. Texila Journal of Public Health, 8(1). https://doi.org/10.21522/TIJPH.2013.08.01.Art022

\section{Copyrights}

Copyright for this article is retained by the author(s), with first publication rights granted to the journal.

This is an open-access article distributed under the terms and conditions of the Creative Commons Attribution license (http://creativecommons.org/licenses/by/4.0/). 